\title{
General practitioner residency consultations: video feedback analysis
}

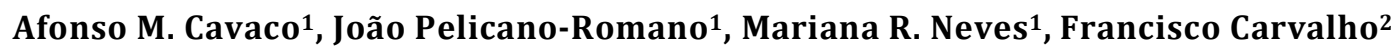

\author{
${ }^{1}$ Research Institute for Medicines and Pharmaceutical Sciences (iMed.UL), Faculty of Pharmacy, University of Lisbon, \\ Av. Prof. Gama Pinto, Portugal \\ ${ }^{2}$ General and Family Medicine Residency South Zone, Lisbon, Portugal
}

Correspondence: Afonso M. Cavaco, Research Institute for Medicines and Pharmaceutical Sciences (iMed.UL) Faculdade de Farmácia da Universidade de Lisboa, Av. Prof. Gama Pinto, 1649-003 Lisboa, Portugal.

Email: acavaco@ff.ul.pt

\begin{abstract}
Objectives: The purpose of this study was to analyse longitudinally two decades of Portuguese general practitioner (GP) residents' consultation features, such as consultation length- estimating its major determinants- as well as to compare with GP residents from other Western practices. Methods: This pilot study followed a retrospective and descriptive design, comprising of the analysis of videotaped consultations with real patients from GP residents (southern Portugal), between 1990 and 2008. Main studied variables were consultation length and purpose, participant demographics and residency site characteristics.

Results: From 516 residents, $68.0 \%$ were females, mainly between 26-35 years old (50.6\%). Female patients' proportion equalled doctors', with the most frequent age group being the 46-65 years old (41.3\%). The consultation took on average 22 minutes and 22 seconds, with no significant
\end{abstract}

differences by year and residency location. Main consultation purposes were previous scheduling (31.6\%) and acute symptoms (30.0\%). Duration was consistently longer than practising GPs from other countries, keeping in mind the supervised practice. Significant and positive predictors of consultation length were number of attendants and patients' frequency at the residency site.

Conclusions: South Portugal GP residency program consultations were lengthier in comparison to similar practice in Europe and other Western countries. Length correlated preferably with patient related variables than with professionals', while confirming the longitudinal homogeneity in the residency consultation format for the last two decades.

Keywords: Family medicine, residency, consultation length, video feedback, Portugal

\section{Introduction}

It is well accepted the role of General and Family Medicine (GFM) in health care. GFM has been considered the first link between patient and medical services, enabling access to other specialities and health professionals. GFM professionals deal with patients and their families, performing caring societal roles amidst the community in which they are integrated. ${ }^{1}$

In 2007, there were in Portugal 62.7 general practitioners (GPs) per 100.000 inhabitants. These professionals have presented a steady or declining number in the last decade, contributing to a probable increase of inadequate primary health care. ${ }^{2}$ Since 1981, Portuguese medical graduates have accessed GFM by attending post-graduate education, a three years residency programme. ${ }^{3}$ To accomplish this specialization, the present regulations require residents to perform 33 months of effective training in all major areas of primary care and general practice, e.g. obstetrics, paediatrics, emergency medicine, mental health, etc. Residency sites are located in public health centres from the National Health Service (NHS) and Portuguese trainees, as well as foreign physicians, receive practical education and perform real patient consultations supervised by a tutor. After completing the training, most GPs will work for the NHS, although some might choose a private practice too. The 
programme coordination is geographically divided in three regions, North, Centre, and South, with equivalent training goals. The South region has long implemented a video consultation feedback at the $2^{\text {nd }}$ residency year, as a way to assess the medical interviewing skills of their residents.

Video feedback is one of several educational methods used to assess consultation skills. ${ }^{4}$ Reviewing videotaped interviews has been considered a valuable and wellestablished learning tool for improving communication skills in the medical setting, affording a good opportunity for individual reflection upon one's own interviewing competencies. ${ }^{5,6}$ In the present case, the resident and a multidisciplinary assessment board, comprising of the tutor, a residency coordinator and a clinical psychologist, listen to the video tape and to the resident's self-appraisal so can subsequently provide a commentary on the clinical case resolution and on the resident's communication and interactional performance. Since 1990, the General and Family Medicine Residency Coordination - South Zone (GFMRC-SZ) has preserved and stored this video library, a valuable information source. A systematic analysis of such a database provides an interesting picture of basic consultation features and its evolution such as consultation length and how it might have been influenced by determinants e.g. consultation purpose, and physician and patient characteristics. $^{7}$

GPs are intended to follow up patients' and relatives' health problems. It is through the interaction made available by interviewing patients that care may be provided and relationships are established, all having implications during the course of time. ${ }^{8}$ Consultation length has been proposed as an indicator of the quality of consultation in general practice. ${ }^{9-12}$ Although this has been questioned, ${ }^{13,14}$ longer consultations were found to be associated with greater patient enablement and satisfaction. ${ }^{15,16}$ Besides educational tools, consultation tapes also reflect the actual practice at the time of recording. Having access to a set of residency tapes from almost two decades of general practice provides a good perspective of how residency consultation has evolved and what major determinants might have been influencing consultation key features, such as consultation length.

This study aimed to describe longitudinally elemental features from videotaped consultations of primary care residents, in particular consultation length, as a surrogate measure of their quality. It was also aimed to evaluate possible determinants of consultation length, such as patients and physician demographics, interview characteristics and residency site attributes.

\section{Methods}

The study followed a retrospective descriptive design. Data was obtained from a video bank comprising of real patient consultations performed by primary care residents from South Portugal (GFMRC-SZ) and corresponding additional files. Tapes and written information were content analysed in relation to variables of interest by two independent researchers.

\section{Participants}

Participants' videos were recorded between 1990 and 2008, for all $2^{\text {nd }}$ year GFMRC-SZ interns. These tapes allow constructive feedback to be given about resident's instrumental and socio-emotional communication by a residency coordination panel, which includes the tutor, a general practitioner specialist and a psychologist.

Key variables and information were collected from tapes and additional material that comprised of participants' demographics, residency geographical location, consultation length and other elemental features.

From the period under analysis, it was possible to find additional information for residency years 2004 and 2005 in Portugal, comprising of GPs and patients' distribution by residency site i.e. the total number of medical practitioners and patients in each healthcare centre. This allowed investigation of influences on consultation length including an estimate of GP utilization, corresponding to a surrogate measure of professionals' workload.

\section{Data Analysis}

Residents' and patients' demographics, as well as consultation related features (e.g. purpose and duration) were statistically compared by year and residency location. In addition, a literature review was performed on PubMed, ERIC and PsycINFO. The keywords used were "length" or "duration" and "consultation", "visit", "interview" or "encounter". This was limited to primary care, general or family medicine resident or intern consultations, with real patients (no standardized or simulated patients). The time period was from 1990 to 2008; this allowed to obtain relevant references and to contextualize consultation length within the primary care practice.

Using the data from 2004 and 2005, a multiple linear regression model was computed, using a stepwise method, with qualitative predictors transformed into dummy independent variables. The predicators and these variable types that were entered into the model calculation were:

1. Demographics

a. Resident and patient gender, binary (male/female)

b. Resident age, binary (under $36 / 36$ and above)

c. Patient age, binary (elderly $\geq 65 /$ non elderly $<65$ )

d. Nationality, binary (Portuguese/non-Portuguese)

2. Residency

a. Residency year, continuous

b. Consultation purpose, dummy binary (reference category Routine)

c. Number of attendants, continuous

d. Personal interference, binary (0 no personal interference)

3. Location 
a. District, dummy binary (reference category Lisbon)

b. Number of GPs by site, continuous

c. Number of patients by site, continuous

d. GP usage rate (or workload), continuous

All data was analysed using the Statistical Package for Social Sciences (IBM PASW Statistics 18) and significance level set to $\mathrm{p}<0.05$ for all statistical tests.

\section{Ethical considerations}

The project received ethical approval from the Residency Coordination. Written informed consent was obtained from both residents and patients to allow video recording for educational and research purposes. An external ethics committee in healthcare research (Research Unit in Health Sciences - Coimbra, Portugal), had also granted overall formal ethical approval.

\section{Results}

From 1990 to 2008, there were 516 residents with at least one videotaped consultation ( $71.5 \%$ ), while $28.5 \%$ provided two or more tapes. There was no statistical association between residency location (district) and the average number of tapes sent. When there was more than one tape available per resident, the first tape submitted was considered as GFMRC-SZ.

\section{Demographic information}

Table 1 presents the main demographics for residents and patients. There was an equal distribution of gender, with $68 \%$ females in both residents and patients. Residents most represented age group was $25-36$ years (50.6\%), being $80.4 \%$ Portuguese, whilst patients most represented cohort was 46-65 years (41.3\%), composed mostly of Portuguese citizens $(95.9 \%)$.

Table 2 presents residents distribution over nearly 2 decades, a number which has increased over time and ranges from 7 (1990) to an average of 41 residents per year $(2001=42,2005=41,2007=40)$. With the exception of 1990 , where video feedback was optional and the actual number of residents is underrepresented (52\%), all other years comprise at least $87 \%$ of the total cohort. Missing tapes were due to logistical issues, namely misplacement and loss. A majority (41.3\%) did their residency in Lisbon, followed by the south neighbouring district of Setubal (11.5\%), while only $3.1 \%$ were based in the southern Beja district. It was not possible to find the exact residency location for $15.5 \%$ of the residents.

\section{Consultation features and length}

GP residents video consultations and their elemental features are presented in Table 3, such as the main purpose for consultation, number of attendants and potential interferences. This last feature comprised of the presence of a $3^{\text {rd }}$ party, such as a nurse or administrative staff, actively interrupting the consultation. Phone calls were also considered as interference, even if the resident would not answer, as well as environmental interferences e.g. noteworthy background noises. There was only a clear interference in $8.4 \%$ of the tapes.

The main purpose of consultations was classified into eight different categories, the two most frequent being; routine i.e. previously scheduled consultations (31.6\%) and visits resulting from acute symptoms (30.0\%). Most consultations were recorded with just the patient present, although $17.1 \%$ had an accompanying person.

From 19 consecutive years of recordings, the average consultation length was $22 \mathrm{~min}$ : $22 \mathrm{sec}$ (SD 9min: $44 \mathrm{sec}$ ). The minimum length was $02 \mathrm{~min}: 04 \mathrm{sec}$ while the maximum was 1:02:29 (hr:min:sec). The first quartile (25 percentile) was therefore a duration of $15 \mathrm{~min}: 30 \mathrm{sec}$. The mean consultation length by year is shown in Figure 1. Figure 1 also shows reference values by country and year showing practising GPs consultation length. These values, which are consistently and significantly smaller than interns values, only aim to contextualize duration and are not directly comparable. No data was found representing primary care residents or interns consultation length in different regions or countries.

Table 1. Residents and patients demographics $(\mathrm{N}=516)$

\begin{tabular}{|c|c|c|}
\hline Variable & $\begin{array}{l}\text { Residents } \\
\mathrm{n}(\%)\end{array}$ & $\begin{array}{c}\text { Patients } \\
\mathrm{n}(\%)\end{array}$ \\
\hline \multicolumn{3}{|l|}{ Gender } \\
\hline Female & $351(68.0)$ & $351(68.0)$ \\
\hline Male & $165(32.0)$ & $165(32.0)$ \\
\hline \multicolumn{3}{|l|}{ Age } \\
\hline $0-3$ & -- & $22(4.3)$ \\
\hline $4-18$ & -- & $14(2.7)$ \\
\hline $19-25$ & -- & $14(2.7)$ \\
\hline $26-35$ & $261(50.6)$ & $43(8.3)$ \\
\hline $36-45$ & $199(38.6)$ & $71(13.8)$ \\
\hline $46-65$ & $56(10.8)$ & $213(41.3)$ \\
\hline$>65$ & -- & 139 (26.9) \\
\hline \multicolumn{3}{|l|}{ Nationality } \\
\hline Portuguese & $415(80.4)$ & 495 (95.9) \\
\hline Spanish * & $68(13.2)$ & $1(0.2)$ \\
\hline Brazilian * & $5(1.0)$ & $1(0.2)$ \\
\hline PALOP $^{\dagger}$ & $17(3.3)$ & $16(3.1)$ \\
\hline Eastern Europeans * & $9(1.7)$ & $3(0.6)$ \\
\hline Other (e.g. Asian) * & $2(0.4)$ & -- \\
\hline
\end{tabular}

* Most of them graduated in their home countries

† African Portuguese speaking nationals were graduated in Portugal 
Table 2. Number of residents per year and district $(\mathrm{N}=516)$

\begin{tabular}{|c|c|c|}
\hline \multicolumn{3}{|c|}{ Number of residents per year } \\
\hline Year & $\mathrm{n}$ & $\%$ \\
\hline 1990 & 7 & 1.4 \\
\hline 1991 & 18 & 3.5 \\
\hline 1992 & 14 & 2.7 \\
\hline 1993 & 18 & 3.5 \\
\hline 1993 & 29 & 5.6 \\
\hline 1995 & 20 & 3.9 \\
\hline 1996 & 16 & 3.1 \\
\hline 1997 & 26 & 5.0 \\
\hline 1998 & 27 & 5.2 \\
\hline 1999 & 38 & 7.4 \\
\hline 2000 & 37 & 7.2 \\
\hline 2001 & 42 & 8.1 \\
\hline 2002 & 33 & 6.4 \\
\hline 2003 & 28 & 5.4 \\
\hline 2004 & 27 & 5.2 \\
\hline 2005 & 41 & 7.9 \\
\hline 2006 & 34 & 6.6 \\
\hline 2007 & 40 & 7.8 \\
\hline 2008 & 21 & 4.1 \\
\hline Total & 516 & 100 \\
\hline \multicolumn{3}{|c|}{ Number of residents per district } \\
\hline Lisbon & 213 & 41.3 \\
\hline Setúbal & 59 & 11.5 \\
\hline Santarém & 49 & 9.5 \\
\hline Faro & 43 & 8.3 \\
\hline Évora & 30 & 5.8 \\
\hline Portalegre & 26 & 5.0 \\
\hline Beja & 16 & 3.1 \\
\hline Missing & 80 & 15.5 \\
\hline Total & 516 & 100 \\
\hline
\end{tabular}

No significant differences in the average consultation length ( $p>0.05$ ) were found between only of the 19 years, although 1994, 2001 and 2002 present noticeably briefer interviews than for instance 1999 and 2005. When compared, the length of taped consultations for male and female residents had no significant difference. Furthermore, residents who accomplished presenting the usual education progression (i.e. younger than 36 years old) and those that accomplished their residency programme later in life (i.e. 36 years of age and older) also showed no significant differences in consultation length.

This was also true between interns from different residency locations (districts), whether an interference occurred or not in the consultation and if the patients were accompanied by another person or were alone.

On the contrary, consultation purpose seemed to have had a significant effect on duration $\left(\mathrm{F}_{(7,506)}=2.071, \mathrm{p}=0.045\right)$, with post-hoc testing (Tamhane's correction) revealing statistically shorter interviews for paediatric patients than for the three most frequent consultations: routine $(p=0.007)$, emergency $(p=0.025)$ and examination follow-up $(\mathrm{p}=0.007)$. Residents nationality also caused another difference $\left(\mathrm{F}_{(5,510)}=2.892, \mathrm{p}=0.014\right)$, with Spanish interns presenting significantly shorter interviews when compared to Portuguese (Tamhanhe's $\mathrm{p}=0.004$ ) and Eastern Europeans (Tamhanhe's $\mathrm{p}=0.015$ ).

\section{Regression results}

In the years 2004 and 2005 there were 68 GFM residents, while the average number of practising GPs per residency site was $33.8(\mathrm{SD}=13.8)$ and average number of patients equalled $32604.3(\mathrm{SD}=13140.4)$. The estimate of GP usage was on average 1041.6 $(\mathrm{SD}=457.2)$ patients per physician per year and no significant differences were found between residency districts.

Regression results revealed two independent variables as significant predictors of consultation length: the number of consultation attendants and the number of patients using the healthcare site. The regression model was significant $\left(\mathrm{F}_{(2,56)}=8.204, \mathrm{p}=0.001\right)$, with $22.7 \%$ explained variance $(\mathrm{r}=0.476)$. Table 4 presents the model coefficients and collinearity statistics.

According to regression results, if an accompanying person was in the room, the consultation length increased on average $628 \mathrm{sec}$ (i.e. approximately $10 \mathrm{~min}$ ) although this second person was not sick role so keeping the other independent variable constant. This variable has more impact on consultation length than one unit increase in the number of residency site users. Variables such as consultation purpose or the residents nationality were not significant predictors of residents consultation length.

Table 3. Characteristics of the consultation and clinical activity $(\mathrm{N}=516)$

\begin{tabular}{|c|c|c|}
\hline Consultation and clinical activity & $\mathrm{n}$ & $\%$ \\
\hline \multicolumn{3}{|l|}{ The main purpose of consultation } \\
\hline Routine, previously scheduled & 163 & 31.6 \\
\hline Emergency, acute symptoms & 155 & 30.0 \\
\hline Follow-up, showing exams & 119 & 23.1 \\
\hline Paediatrics* & 38 & 7.4 \\
\hline Follow-up, medication prescription & 18 & 3.5 \\
\hline Follow-up, obstetrics & 11 & 2.1 \\
\hline Family planning & 5 & 1.0 \\
\hline Administrative (e.g. sick leave) & 7 & 1.3 \\
\hline \multicolumn{3}{|l|}{ Number of attendance ${ }^{*}$} \\
\hline 1 (patient only) & 428 & 82.9 \\
\hline 2 (patient +1 accompany) & 81 & 15.7 \\
\hline 3 (patient +2 accompanies) & 7 & 1.4 \\
\hline \multicolumn{3}{|l|}{ Environmental interference } \\
\hline No & 512 & 99.2 \\
\hline Yes & 4 & 0.8 \\
\hline \multicolumn{3}{|l|}{ Personal interference } \\
\hline No & 473 & 91.6 \\
\hline \multicolumn{3}{|l|}{$3^{\text {rd }}$ party presence } \\
\hline Active & 37 & 7.2 \\
\hline Passive & 6 & 1.2 \\
\hline
\end{tabular}

* If the patient was a child with less than 3 years of age, the child and the parent were considered as one attendance for analysis. 


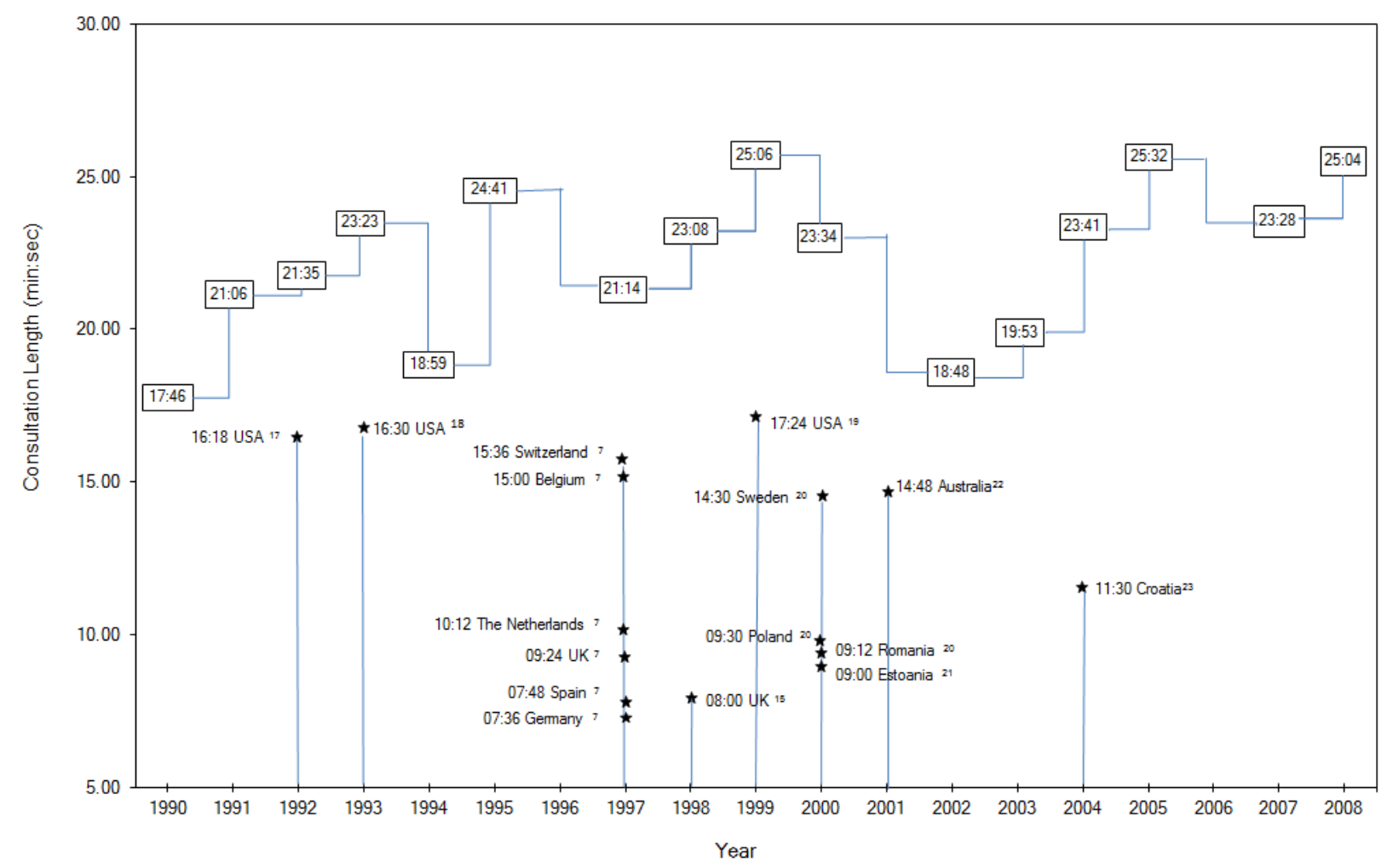

Figure 1. GFMRC-SZ consultation length from 1990 to 2008 (interpolation line, left step)

$\star$ Consultation length in different countries

Table 4. Regression model coefficients* and predictors collinearity

\begin{tabular}{|c|c|c|c|c|c|c|c|}
\hline \multirow{2}{*}{ Model } & \multicolumn{2}{|c|}{ Unstandardized coefficients } & \multirow{2}{*}{$\begin{array}{c}\text { Standardized coefficients } \\
\text { Beta }\end{array}$} & \multirow{2}{*}{$\mathrm{t}$} & \multirow{2}{*}{$P$ value } & \multicolumn{2}{|c|}{ Collinearity statistics } \\
\hline & B & Std. Error & & & & Tolerance & VIF \\
\hline (Constant) & 309.087 & 302.777 & & 1.021 & 0.312 & & \\
\hline Number of attendants & 628.474 & 197.259 & 0.375 & 3.186 & 0.002 & 0.989 & 1.011 \\
\hline Number of $\mathrm{HC}$ patients & 0.014 & 0.006 & 0.283 & 2.410 & 0.019 & 0.977 & 1.023 \\
\hline
\end{tabular}

* Dependent Variable: Consultation length (in sec) HC - Healthcare Centres

\section{Discussion}

The GFMRC-SZ residency is a medical post-graduate and professional specialization that has shown a growing number of residents along the period studied. Reasons for this increase in GFM professionals may be related to expanding medical education (e.g. the opening of new faculties) as well as governments' political efforts to assure primary healthcare coverage, resulting in high demand on residency vacancies. ${ }^{24}$

As expected, Lisbon presented the greatest number of residents per year, corresponding to a high population density and the greatest number of healthcare centres $(n=45)$, which are the residency site per excellence. This correlation was confirmed for all districts, with most isolated districts (e.g. Beja) presenting a lower number of residents. The majority of residents were under 36 years of age, although mature adults have also been engaged on initiating a medical GFM career, suggesting a population demand and governmental efforts to increase GPs numbers. On the other hand, patients' tapes comprised both paediatric and geriatric populations. These patient groups and associated health problems confirm residents' exposure to a diversified training, while some encounters may have posed additional cultural and/or linguistic challenges. Actually, residents who do not have a Portuguese background performed significantly different from national interns in relation to consultation length.

Assuming awareness of video recording as having nonsignificant effect on consultations length ${ }^{25}$, GFMRC-SZ residents' consultation duration was consistently longer than reference values obtained from the literature reviewalways above $15 \mathrm{~min}$ in duration. As previously referred, even if caution is needed when comparing these values, due 
to several anticipated differences it should be noticed that residents' tapes were recorded with real patients in common consultations, whilst under guidance of a practising GP. Keeping in mind the existing differences, in particular those between internship and real practice, it was not expected to have doubled residents' consultation length compared to practising GPs in all years studied. According to The Euro communication studies, the European consultation length is around $11 \mathrm{~min} .{ }^{7,20,26}$ Residents' tapes show a longer contact with the patient and this may be associated with the provision of more detailed care, which in turn might increase patient satisfaction, decrease prescription rates and return visits. ${ }^{9,10,12}$ On the other hand, longer interviews suggest these medical trainees' might be less efficient in conducting patient consultations, taking extra time to perform the necessary tasks. Interestingly, a cultural factor might play a role here too, since Spanish residents conducted shorter interviews. Whilst initially this could be considered a language issue, residents from other nationalities, such as Eastern Europeans, also had longer interviews than Spanish residents. In fact, this seems to correlate with Spanish practising GPs in their own country, who are amongst the practitioners with shorter consultations in Europe. ${ }^{7,20,26}$

Consultation length was also sensitive to the main reason why patients were visiting primary healthcare. As in previous studies ${ }^{13}$ paediatric consultations were the shortest, and this can be explained be existing referral system. However, emergency consultations did not differ from routine, i.e. new health problems did not increase length in comparison with old ones, as described by Deveugele and colleagues. ${ }^{7}$ This suggests that residents performing followup consultations might have used the time saved on instrumental communication, which is not critical for former health problems, in socio-emotional or affective communication with the patient. This needs further confirmation by a content analytical method. Nonetheless, length uniformity during two decades of video recording suggests a perpetuation of a practice model, with probable standardization of training methods. This issue should receive additional attention from researchers in future studies.

From a set of possible consultation length predictors, the significant ones were the number of attendants per consultation and the volume of patients served at the residency site. While the first predictor was expected, noting that accompanying persons were not performing a sick role, an increase in consultation length explained by an increase in the number of healthcare users seems somehow contradictory. Knowing the usual limitations in human resources, an increase in services demand should decrease the average time GPs spend with each patient, also influencing residents' practice on average. While additional independent variables were not addressed (e.g. familiarity, verbal and non-verbal behaviour), those found to be significant predic- tors were patient related variables. This suggests in subsequent studies an evaluation of patient related variables, e.g. educational level and percentage of time spent in discussing psychosocial and emotional problems.

\section{The limitations of the study}

Main study limitations were associated with disrupted segments of the databank. While tapes were all in readable conditions, additional information on practice sites or residents' features was not always accessible or complete. Thus, hoe representative the results are is limited, in particular for the multilevel analysis. A further imitation is that although all residents' consultations have followed recording guidelines, it is not safe to say they were a true reflection of the residency practice. No published studies with GP interns consultation length in Portugal and other countries, limited any comparisons to be made. The concurrent use of other analytical methods, adequate to unveil the consultation content, e.g. Roter Interaction Analysis System (RIAS), would detail these consultations and allow for other explanatory variables.

\section{Conclusions}

In the two last decades, without interruption, practising Portuguese GPs have received training through the use of video feedback. Consultations length was quite homogenous during this period, suggesting no significant changes on the overall consultation format. Although there are differences related for instance with residents' nationality, consultation length seem to depend more on patient and health services users than on professional features. Further analysis is needed to confirm and detail these results.

Even though it was not possible to determine the actual impact on training and practice from video feedback, its acceptance by residents and exclusiveness in the national GP education are good reasons to continue using of this valuable educational tool. In addition, keeping such a databank showed to be a value opportunity for tracking education features and their evolution.

\section{Acknowledgments}

The authors would like to thank the residency coordinators, in particular Drs Ricardina Barroso and Francisco Carvalho. This work has been supported by Fundação para a Ciência e Tecnologia, Grant Ref. PTDC/SAU-ESA/098006/2008.

\section{Conflict of Interest}

The authors declare that they have no conflict of interest.

\section{References}

1. World Health Organization. WHO definition of primary health care 2011. 2011 [cited 23 June 2011]. Available from: http://www.who.int/topics/primary_health_care/en/.

2. Gaspar D. General and family medicine: a gratifying choice. Acta Med Port. 2006;19:133-9. 
3. Gaspar D. General practice and family medicine vocational training: the specialty residency doctor's profile, in Portugal. Acta Med Port. 2010;23:39-50.

4. Edwards A, Tzelepis A, Klingbeil C, Melgar T, Speece $\mathrm{M}$, Schubiner $\mathrm{H}$, et al. Fifteen years of a videotape review program for residential medicine and medicine-paediatrics residents. Acad Med. 1996;71:744-8.

5. Parish SJ, Weber CM, Steiner-Grossman P, Milan FB, Burton WB, Marantz PR. Teaching clinical skills through videotape review: a randomized trial of group versus individual reviews. Teach Learn Med. 2006;18:92-8.

6. Chou C, Lee K. Improving residents' interviewing skills by group videotape review. Acad Med. 2002;77:744.

7. Deveugele M, Derese A, van den Brink-Muinen A, Bensing J, De Maeseneer J. Consultation length in general practice: cross sectional study in six European countries. BMJ. 2002;325:472.

8. Allen J, Gay B, Crebolder H, Heyrman J, Svab I, Ram P, et al. The European Definition of General Practice/Family Medicine - Short Version, EURACT 2005. Rev Port Clin Geral. 2005;21:511-6.

9. Hull FM, Hull FS. Time and the general practitioner: the patient's view. J R Coll Gen Pract. 1984;34:71-5.

10. Wilson A. Consultation length in general practice: a review. Br J Gen Pract. 1991;41:119-22.

11. van Berkestijn LG, Kastein MR, Lodder A, de Melker RA, Bartelink ML. How do we compare with our colleagues? Quality of general practitioner performance in consultations for non-acute abdominal complaints. Int J Qual Health Care. 1999;11:475-86.

12. Freeman GK, Horder JP, Howie JG, Hungin AP, Hill AP, Shah NC, et al. Evolving general practice consultation in Britain: issues of length and context. BMJ. 2002;324:8802.

13. Carr-Hill R, Jenkins-Clarke S, Dixon P, Pringle M. Do minutes count? Consultation lengths in general practice. J Health Serv Res Policy. 1998;3:207-13.

14. Druss B, Mechanic D. Should visit length be used as a quality indicator in primary care? Lancet. 2003;361:1148.

15. Howie JGR, Heaney DJ, Maxwell M, Walker JJ, Freeman GK, Rai H. Quality at general practice consultations: crosssectional survey. BMJ. 1999;319:738-43.
16. Ogden J, Bavalia K, Bull M, Frankum S, Goldie C, Gosslau M, et al. "I want more time with my doctor": a quantitative study of time and the consultation. Fam Pract. 2004;21:479-83.

17. Blumenthal D, Causino N, Chang YC, Culpepper L, Marder W, Saglam D, et al. The duration of ambulatory visits to physicians. J Fam Pract. 1999;48:264-71.

18. Levinson W, Roter DL, Mullooly JP, Dull VT, Frankel RM. Physician-patient communication. Relationship with malpractice claims among primary care and surgeons. JAMA. 1997;277:553-9.

19. Tai-Seale M, McGuire T, Zhang W. Time allocation in primary care office visits. Health Serv Res. 2007;42:1871-94. 20. van den Brink-Muinen A, van Dulmen AM, Bensing JM, Maaroos HI, Tähepold H, Plawecka L, et al. Eurocommunication II: a comparative study between countries in Central- and Western-Europe on doctor-patient communication in general practice: final report. Utrecht: NIVEL; 2003 [cited 4 Jul 2011]. Available from: http://www .nivel.nl/pdf/EurocommunicationII.pdf.

21. Tähepold H, Maaroos HI, Kalda R, van den BrinkMuinen A. Structure and duration of consultations in Estonian family practice. Scand J Prim Health Care. 2003;21:167-70.

22. Britt H, Valenti L, Miller G. Time for care. Length of general practice consultations in Australia. Aust Fam Physician. 2002;31:876-80.

23. Ozvacić Adzić Z, Katić M, Kern J, Lazić D, Cerovecki Nekić V, Soldo D. Patient, physician, and practice characteristics related to patient enablement in general practice in Croatia: cross-sectional survey study. Croat Med J. 2008;49:813-23.

24. Outeirinho C. Complementary general practice internship in the north zone: one decade. Rev Port Clin Geral. 2005;21:69-78.

25. Pringle M, Stewart-Evans C. Does awareness of being video recorded affect doctors' consultation behaviour? Br J Gen Pract. 1990;40:455-58.

26. van den Brink-Muinen A, Verhaak PF, Bensing JM, Bahrs O, Deveugele M, Gask L, et al. Communication in general practice: differences between European countries. Fam Pract. 2003;20:478-85. 